\title{
Carcinosarcoma (Metaplastic Carcinoma) Breast: A Rare and Aggressive Primary - Report of Two Cases with Review of Literature
}

\begin{abstract}
Carcinosarcoma (CS) also known as metaplastic carcinoma of the breast is a rare and aggressive type of malignancy with controversial origin. Currently, there are no standard treatment guidelines outlined, owing to the rarity of the disease, but according to the available literature, surgery followed by adjuvant radiation therapy has the greatest benefit. We are presenting two cases of CS of breast developing metastasis. One of the cases presented with lung metastasis during the course of follow-up and responded significantly to chemotherapy, and the other is currently receiving chemotherapy. The cases are being presented here along with the literature review enlightening the current knowledge and available treatment options.
\end{abstract}

Keywords: Carcinosarcoma breast, chemotherapy, metaplastic carcinoma

\section{Introduction}

Carcinosarcoma (CS) breast is an extremely rare malignancy, accounting for about $0.1 \%$ of all primary breast tumors. ${ }^{[1]} \mathrm{CS}$ is defined as tumor exhibiting both carcinomatous and sarcomatous components (malignant nonepithelial component of mesenchymal origin), without evidence of a transition zone between the two elements. ${ }^{[2]}$ The exact cell of the origin of CS is not known, but it is believed to be sarcomatoid metaplasia of carcinoma cells. ${ }^{[3]}$ Herein, we report two rare cases of CS breast, along with the review of literature.

\section{Case Reports}

\section{Patient 1}

A 50-year-old postmenopausal female presented in August 2012 with lump in the left breast for 3 months. The patient was diagnosed as carcinoma left breast with clinical stage T2N1M0 after complete clinicoradiological evaluation. Tru-cut biopsy revealed CS. The patient underwent left-sided modified radical mastectomy in September 2012. She was given six cycles of chemotherapy with mesna, ifosfamide, Adriamycin, and dacarbazine (MAID regimen) followed by external beam radiotherapy to a dose of $50 \mathrm{~Gy}$ in 25 fractions to left-sided chest wall. After

This is an open access journal, and articles are distributed under the terms of the Creative Commons Attribution-Non Commercial-ShareAlike 4.0 License, which allows others to remix, tweak, and build upon the work non-commercially, as long as appropriate credit is given and the new creations are licensed under the identical terms.

For reprints contact: reprints@medknow.com
3 years of treatment, the patient presented with breathing difficulty. Whole-body positron emission tomography-computed tomography (PET-CT) showed fluorodeoxyglucose avid right-sided suprahilar, hilar, and infrahilar mass lesion measuring $6.2 \mathrm{~cm} \times 3.1 \mathrm{~cm} \times 5.4 \mathrm{~cm}$ suggestive of metastasis [Figure 1a]. After three cycles of docetaxel and gemcitabine chemotherapy, repeat whole-body PET-CT showed complete remission [Figure 1b]. The patient is currently receiving chemotherapy to complete a total of six cycles.

\section{Patient 2}

A female patient presented to us in November 2016 with a chief complaint of lump in the right breast for 1 year. On local examination, the right breast was enlarged with the presence of engorged veins and superficial ulceration and was firm in consistency [Figure 2]. It was fixed to the chest wall. There was no axillary lymphadenopathy. Her general examination was unremarkable. The lump gave a clinical impression of malignant phyllodes tumor. Biopsy from the breast lump was suggestive of CS, with tumor cells showing positivity for both epithelial membrane antigen and vimentin and negativity for ER, PR, HER2Neu, and CK [Figures 3a-c]. Contrast-enhanced CT of the neck, thorax, and abdomen was performed which showed

How to cite this article: Singh GK, Singh P,
Bhowmik KT. Carcinosarcoma (Metaplastic
Carcinoma) breast: A rare and aggressive primary -
report of two cases with review of literature. Indian J
Med Paediatr Oncol 2018;39:400-4.

\section{Gunjesh Kumar \\ Singh, Pragya Singh", KT Bhowmik}

Departments of Radiotherapy and ${ }^{~}$ Pathology, VMMC and Safdarjung Hospital, New Delhi, India

Address for correspondence: Dr. Gunjesh Kumar Singh, Department of Radiotherapy, VMMC and Safdarjung Hospital, New Delhi - 110 029, India. E-mail: gunjeshsingh00764@ gmail.com

Access this article online Website: www.ijmpo.org DOI: 10.4103/ijmpo.ijmpo_27_17 Quick Response Code:

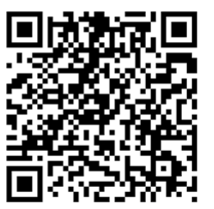


a large heterogeneously enhancing mass, with necrotic and cystic areas measuring $10 \mathrm{~cm} \times 16 \mathrm{~cm} \times 13.5 \mathrm{~cm}$, replacing whole of the right breast along with the presence of bilateral lung metastasis [Figure 4]. The patient's blood parameters were normal. She was discussed in multidisciplinary clinic and planned for chemotherapy with MAID regimen. The patient is currently receiving the same and is tolerating well.

\section{Discussion}

Breast cancer is currently the most common malignancy seen in females worldwide. ${ }^{[4]}$ The most common histology is that of infiltrating ductal carcinoma (IDC). ${ }^{[5]} \mathrm{CS}$ arising in the breast is a rare phenomenon and is aggressive in behavior with a poor clinical course. CS is a general term used for biphasic tumors showing the presence of both malignant epithelial and mesenchymal components in the same tumor. It was first described by Huvos et al. in 1973. ${ }^{[6]}$ They are believed to have a distinct behavior and clinical course that is different from either carcinoma or sarcoma. ${ }^{[3]}$

\section{Clinical features of carcinosarcoma breast}

Breast CS often presents in a way clinically similar to IDC. ${ }^{[2]}$ The patient commonly presents with painful lump in the breast, while the presence of nipple discharge, nipple

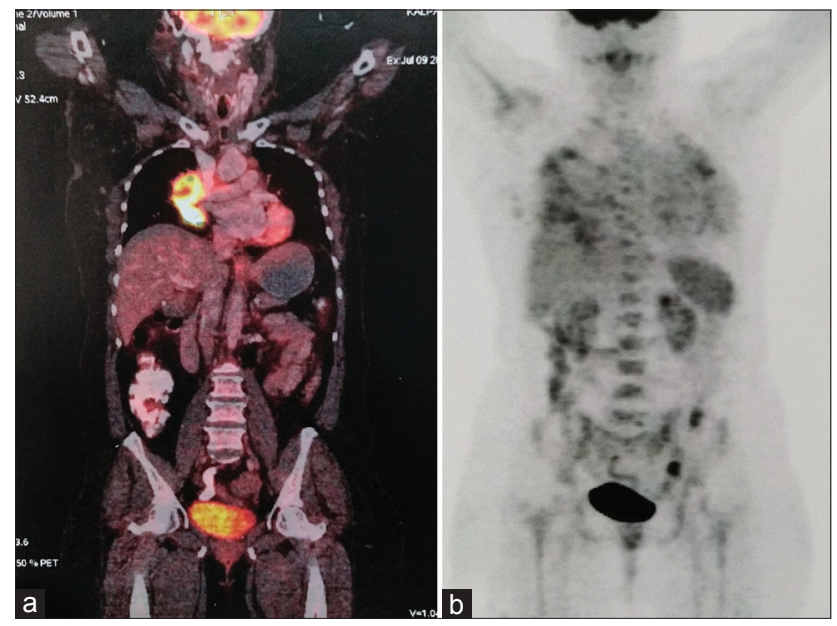

Figure 1: (a) (Whole-body positron emission tomography-computed tomography) - Fluorodeoxyglucose avid right-sided suprahilar, hilar, and infrahilar mass lesion measuring $6.2 \mathrm{~cm} \times 3.1 \mathrm{~cm} \times 5.4 \mathrm{~cm}$ (suggestive of metastasis). (b) (Whole-body positron emission tomography-computed tomography) - No significant fluorodeoxyglucose avid lesion in the body

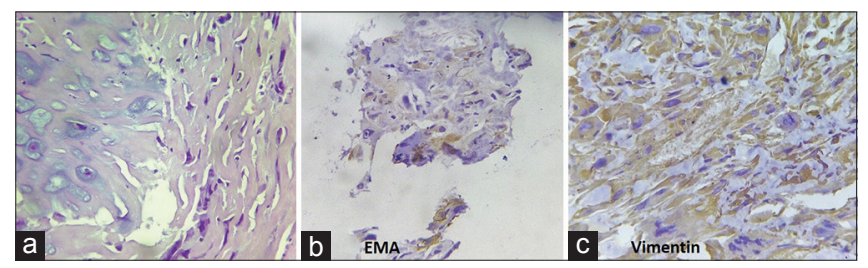

Figure 3: (a) Pleomorphic malignant tumor cells seen infiltrating into fibrocollagenous tissue $(\times 40)$. (b and c) Immunohistochemistry: Tumor cells are positive for epithelial membrane antigen and vimentin retraction, or skin ulceration is rarely seen in this entity. ${ }^{[7]}$ It is commonly seen in females of age more than 50 years. ${ }^{[8]}$ The lung is the most common site of visceral metastasis followed by brain, bone, and liver. ${ }^{[9]}$ Axillary lymph node involvement is seen in about $8 \%-40 \%$ of the cases. ${ }^{[10]}$

\section{Pathogenesis and histopathological features}

The exact etiopathogenesis and origin of CS breast are controversial. It is postulated that they have myoepithelial cell origin. According to the literature, cystosarcoma phyllodes, fibroadenoma, and other cystic diseases of breast may be the possible causative factors. ${ }^{[3,11]}$ Immunohistochemistry has the prime role in the definitive diagnosis of $\mathrm{CS}^{[12]}$ According to Wargotz et al., the sarcomatous component shows positivity for $\mathrm{CK}$ in $55 \%$ of cases and vimentin in $98 \%$ of cases. ${ }^{[13]}$ Unlike adenocarcinoma (ductal and lobular carcinoma) breast, the tumor is usually negative for estrogen, progesterone, and HER2/neu (75\%-85\%). They show an overexpression of the epidermal growth factor receptor gene (EGFR/ HER1). ${ }^{[14,15]}$ Like stem cells, tumor cells show positivity for CD44 and negativity for CD24. ${ }^{[16]}$ GATA3-regulated genes are responsible for cell-to-cell adhesion,

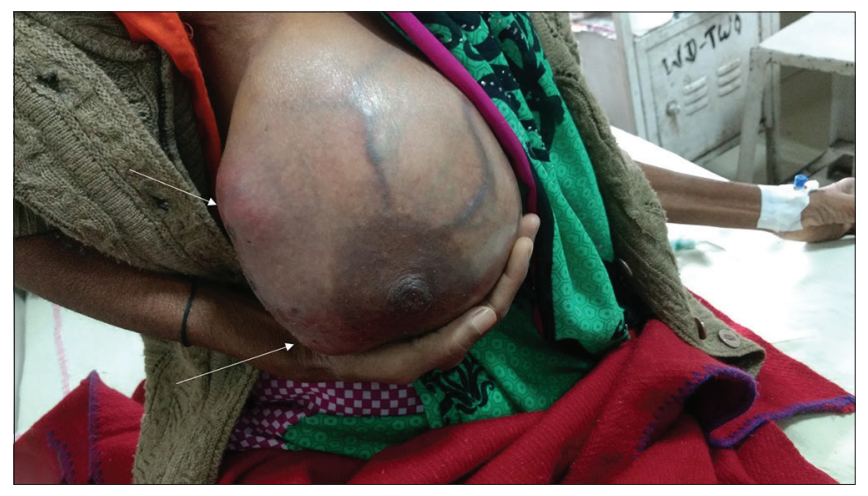

Figure 2: Enlarged right breast with engorged veins and superficial ulcers (arrow) on the surface

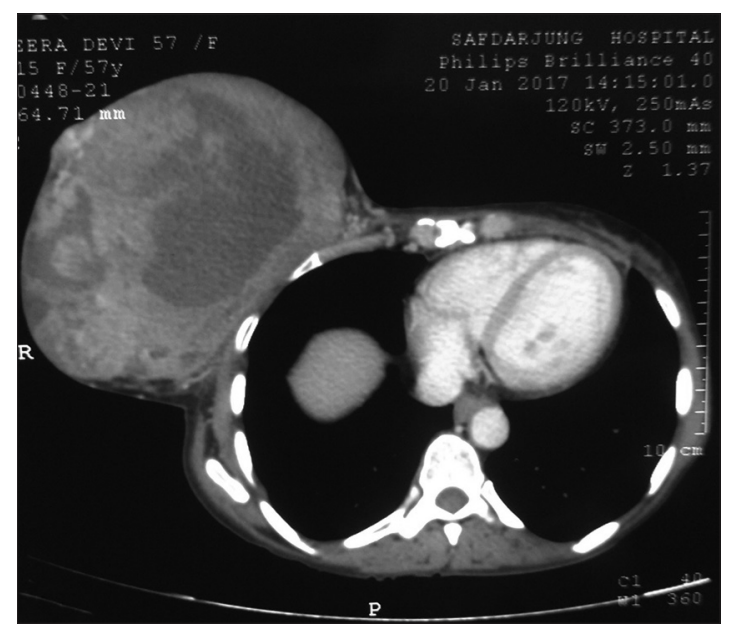

Figure 4: (Contrast-enhanced computed tomography thorax) - Heterogeneously enhancing mass with necrotic and cystic areas measuring $10 \mathrm{~cm} \times 16 \mathrm{~cm} \times 13.5 \mathrm{~cm}$, replacing whole of the right breast 
epithelial-to-mesenchymal transition, and stem cell-like features. The minimal expression of these GATA3-regulated genes makes these tumors relatively chemoresistant. The knowledge of various receptors and genes (therapeutic targets) involved in CS breast can lead to the development of newer treatment strategies. ${ }^{[17]}$

\section{Investigations and workup}

Like adenocarcinoma breast, mammography, ultrasonography, and magnetic resonance imaging aid in the diagnosis of CS breast with histopathological examination followed by immunohistochemistry, being confirmatory also helping in defining the subtypes (epithelial component may be in the form of undifferentiated carcinoma, adenocarcinoma, in situ carcinoma, IDC, or squamous carcinoma, while mesenchymal component may be composed of undifferentiated mesenchymal, fibroblastic, chondroblastic, or osteoblastic areas)..$^{[7,10,18,19]}$

\section{Differential diagnosis}

Table 1 is showing the differential diagnoses of CS breast with their differentiating features. ${ }^{[10,20]}$

\section{Treatment}

The exact treatment of CS breast is unknown, but surgery remains the main treatment like that of IDC. The surgical approach shifted from mastectomy to breast conservation therapy (BCT) in selected patients after NSABP B-06 trial results. ${ }^{[20]}$ Large tumors $(\geq 5 \mathrm{~cm})$ are a relative contraindication to BCT. ${ }^{[21]}$ Surgery with sentinel lymph node biopsy or axillary node dissection followed by postoperative chemotherapy and radiation therapy in various combinations was used in different studies. ${ }^{[4]}$ Owing to the aggressive nature of the tumor, the rates of local recurrence and metastasis are high, so radiation and chemotherapy have a potential role in this entity. According to Lai et al., postmastectomy adjuvant radiotherapy is beneficial in patients with tumor size $\geq 5 \mathrm{~cm}$, skin or chest wall invasion, or with more than four metastatic axillary lymph nodes. ${ }^{[22]}$ Dave et al. treated CS breast with 50-66 Gy of radiotherapy and reported a $10.5 \%$ rate of local recurrence for patients receiving adjuvant radiation after breast conservation surgery (BCS). ${ }^{[23]}$ The chemotherapy regimen which is recommended is anthracycline/taxane-based therapy. ${ }^{[24]}$ In 2006, Hennessy et al. reported no relapse in three patients who had received adriamycin and ifosfamide as treatment. Index patient is also receiving the same chemotherapy regimen. ${ }^{[25]}$ According to Bae et al., patients with triple-negative CS breast have poor 3-year disease-free survival as compared to triple-negative IDC patients receiving the same chemotherapy regimens. ${ }^{[26]}$ Hormone therapy has no role in the management of CS breast. ${ }^{[20]}$ However, HER1/EGFR protein overexpression makes EGFR inhibitors (such as gefitinib and cetuximab) as potential therapeutic targets. ${ }^{[27,28]}$ The molecular studies being carried out for the different genetic and epigenetic aberrations may provide a platform for more targeted and novel treatment options in future. ${ }^{[29]}$

\section{Prognosis and survival}

CS breast is an aggressive malignant tumor with a poorer prognosis than the classical breast carcinomas. Tumor size, type of differentiation, histologic grade, atypia, and presence of active pleomorphic spindle cells play a role in prognosis. ${ }^{[15]}$ Wargotz et al. described 5-year survival rates as $100 \%, 63 \%$, and $35 \%$ for TNM clinical Stages I, II, and III, respectively. ${ }^{[13]}$ According to Beatty et al., 5-year survival rates range from $49 \%$ to $68 \%{ }^{[7]}$ In a retrospective

\begin{tabular}{ll}
\hline \multicolumn{1}{c}{ Table 1: Differential diagnoses of carcinosarcoma and their differentiating features } \\
\hline Clinical condition and differentiating features & CS breast \\
\hline Adenocarcinoma, breast (infiltrating ductal and lobular carcinoma) ${ }^{[10]}$ & $\begin{array}{l}\text { More aggressive } \\
\text { Lower incidence of axillary node involvement } \\
\text { Generally larger tumor size } \\
\text { Mostly triple negative }\end{array}$ \\
$\begin{array}{l}\text { Phyllodes tumor } \\
\text { Mostly benign }\end{array}$ & $\begin{array}{l}\text { Malignant tumor } \\
\text { Benign epithelium with squamous metaplasia }\end{array}$ \\
$\begin{array}{l}\text { Negative for high-molecular-weight keratin and p63 } 3^{[10]} \\
\text { Primary breast sarcoma - epithelial component absent and negative } \\
\text { for keratin and p63 } \\
\text { Pleomorphic adenoma (rare in the breast) }\end{array}$ & $\begin{array}{l}\text { Positive for high-molecular-weight keratin and p63 } \\
\text { Epithelial component present and positive for keratin and p63 }\end{array}$ \\
$\begin{array}{l}\text { Infiltrating margins absent } \\
\text { Epithelial component is not malignant }{ }^{[10]}\end{array}$ & $\begin{array}{l}\text { Infiltrating margins with malignant epithelial component } \\
\text { Nodular fasciitis (proliferative lesion containing fibroblasts and } \\
\text { myofibroblasts in myxoid stroma) }\end{array}$ \\
$\begin{array}{l}\text { Fibromatosis (benign condition with proliferation of fibroblasts })^{[10]} \\
\text { CS - Carcinosarcoma }\end{array}$ & $\begin{array}{l}\text { Keratin positivity differentiates it from nodular fasciitis and } \\
\text { fibromatosis }\end{array}$ \\
\end{tabular}


study, 5-year overall survival rate was reported as 0.73 , $0.59,0.44$, and 0.00 for at Stages I, II, III, and IV, respectively, by Hennessy et al. ${ }^{[25]}$

\section{Conclusion}

$\mathrm{CS}$ is an unusual form of breast malignancy, with only few cases published in the literature. The usual clinical presentation is similar to that of IDC. However, one of our cases presented unusually and raised suspicion of phyllodes tumor. It is challenging to diagnose it preoperatively, even with core needle biopsy and histopathology sometimes. Triple-negativity or basal-like features make it an aggressive neoplasm. Owing to its rarity, there is no standard treatment protocol till now. BCS, mastectomy, and axillary lymph node dissection form the current treatment options similar to IDC. Regardless of the type of surgery used, adjuvant radiation therapy should always be considered. Traditional hormone therapy has no role in the treatment while adriamycin- and taxane-based chemotherapy has some response. The lung lesions in patient 1 responded significantly to docetaxel and gemcitabine, while patient 2 is receiving chemotherapy with MAID regimen. Both will be curiously followed up to know the disease course and response.

\section{Declaration of patient consent}

The authors certify that they have obtained all appropriate patient consent forms. In the form the patient(s) has/have given his/her/their consent for his/her/their images and other clinical information to be reported in the journal. The patients understand that their names and initials will not be published and due efforts will be made to conceal their identity, but anonymity cannot be guaranteed.

\section{Financial support and sponsorship}

Nil.

\section{Conflicts of interest}

There are no conflicts of interest.

\section{References}

1. Srinivas V, Harjai MM, Subramanya H, Rajaram T, Rai R. Carcinosarcoma of the breast with an unusual secretory carcinoma as the carcinomatous component. Med J Armed Forces India 2004;60:410-2.

2. Accurso A, Ciancia G, Della Corte GA, Reale P, Accardo G, Salerno $\mathrm{C}$, et al. A rare case of true carcinosarcoma of the breast. Int J Surg Case Rep 2016;21:125-8.

3. Ilhan E, Vardar E, Ozkok G, Sezgin A, Sahin S, Teker K, et al. A rare tumour of the breast: Carcinosarcoma. J Clin Med Res 2010;2:96-8.

4. Ferlay J, Soerjomataram I, Dikshit R, Eser S, Mathers C, Rebelo $\mathrm{M}$, et al. Cancer incidence and mortality worldwide: Sources, methods and major patterns in GLOBOCAN 2012. Int J Cancer 2015;136:E359-86.

5. Kim SH, Chung HC, Jeong J, Kim JH, Rha SY, Ahn JB, et al. A locally advanced breast cancer with difficult differential diagnosis of carcinosarcoma and atypical medullary carcinoma, which had poor response to adriamycin- and taxane-based neoadjuvant chemotherapy: A case report. Cancer Res Treat 2007;39:134-7.

6. Huvos AG, Lucas JC Jr., Foote FW Jr. Metaplastic breast carcinoma. Rare form of mammary cancer. N Y State J Med 1973;73:1078-82.

7. Beatty JD, Atwood M, Tickman R, Reiner M. Metaplastic breast cancer: Clinical significance. Am J Surg 2006;191:657-64.

8. Shin HJ, Kim HH, Kim SM, Kim DB, Kim MJ, Gong G, et al. Imaging features of metaplastic carcinoma with chondroid differentiation of the breast. AJR Am J Roentgenol 2007;188:691-6.

9. Luini A, Aguilar M, Gatti G, Fasani R, Botteri E, Brito JA, et al. Metaplastic carcinoma of the breast, an unusual disease with worse prognosis: The experience of the European institute of oncology and review of the literature. Breast Cancer Res Treat 2007;101:349-53.

10. McKinnon E, Xiao P. Metaplastic carcinoma of the breast. Arch Pathol Lab Med 2015;139:819-22.

11. Cil T, Altintas A, Pasa S, Buyukbayram H, Isikdogan A. Primary spindle cell sarcoma of the breast. Breast Care (Basel) 2008;3:197-9.

12. Abbasi MA, Mahmood $\mathrm{H}$, Faheem $\mathrm{M}$, Khan KA, Irfan J. Carcinosarcoma of the breast. J Coll Physicians Surg Pak 2012;22:333-4.

13. Wargotz ES, Norris HJ. Metaplastic carcinomas of the breast. III. Carcinosarcoma. Cancer 1989;64:1490-9.

14. Sørlie T. Molecular portraits of breast cancer: Tumour subtypes as distinct disease entities. Eur J Cancer 2004;40:2667-75.

15. Esses KM, Hagmaier RM, Blanchard SA, Lazarchick JJ, Riker AI. Carcinosarcoma of the breast: Two case reports and review of the literature. Cases J 2009;2:15.

16. Hennessy BT, Gonzalez-Angulo AM, Stemke-Hale K, Gilcrease MZ, Krishnamurthy S, Lee JS, et al. Characterization of a naturally occurring breast cancer subset enriched in epithelial-to-mesenchymal transition and stem cell characteristics. Cancer Res 2009;69:4116-24.

17. Reis-Filho JS, Pinheiro C, Lambros MB, Milanezi F, Carvalho S, Savage K, et al. EGFR amplification and lack of activating mutations in metaplastic breast carcinomas. J Pathol 2006;209:445-53.

18. Gurleyik E, Yildirim U, Gunal O, Pehlivan M. Malignant mesenchymal tumor of the breast: Primary chondrosarcoma. Breast Care (Basel) 2009;4:101-3.

19. Pope TL Jr., Fechner RE, Brenbridge AN. Carcinosarcoma of the breast: Radiologic, ultrasonographic, and pathologic correlation. Can Assoc Radiol J 1987;38:50-1.

20. Shah DR, Tseng WH, Martinez SR. Treatment options for metaplastic breast cancer. ISRN Oncol 2012;2012:706162.

21. Poggi MM, Danforth DN, Sciuto LC, Smith SL, Steinberg SM, Liewehr DJ, et al. Eighteen-year results in the treatment of early breast carcinoma with mastectomy versus breast conservation therapy: The national cancer institute randomized trial. Cancer 2003;98:697-702.

22. Lai HW, Tseng LM, Chang TW, Kuo YL, Hsieh CM, Chen ST, et al. The prognostic significance of metaplastic carcinoma of the breast $(\mathrm{MCB})$ - A case controlled comparison study with infiltrating ductal carcinoma. Breast 2013;22:968-73.

23. Dave G, Cosmatos H, Do T, Lodin K, Varshney D. Metaplastic carcinoma of the breast: A retrospective review. Int $\mathrm{J}$ Radiat Oncol Biol Phys 2006;64:771-5.

24. Buzdar AU, Valero V, Theriault RL, Frye D, Green M, Booser D, 
et al. Pathological complete response to chemotherapy is related to hormone receptor status [abstract]. Breast Cancer Res Treat 2003;85:2.

25. Hennessy BT, Giordano S, Broglio K, Duan Z, Trent J, Buchholz TA, et al. Biphasic metaplastic sarcomatoid carcinoma of the breast. Ann Oncol 2006;17:605-13.

26. Bae SY, Lee SK, Koo MY, Hur SM, Choi MY, Cho DH, et al. The prognoses of metaplastic breast cancer patients compared to those of triple-negative breast cancer patients. Breast Cancer Res Treat 2011;126:471-8.

27. Okubo S, Kurebayashi J, Otsuki T, Yamamoto Y, Tanaka K,
Sonoo $\mathrm{H}$, et al. Additive antitumour effect of the epidermal growth factor receptor tyrosine kinase inhibitor gefitinib (Iressa, ZD1839) and the antioestrogen fulvestrant (Faslodex, ICI 182,780) in breast cancer cells. Br J Cancer 2004;90:236-44.

28. Leibl S, Moinfar F. Metaplastic breast carcinomas are negative for her-2 but frequently express EGFR (Her-1): Potential relevance to adjuvant treatment with EGFR tyrosine kinase inhibitors? J Clin Pathol 2005;58:700-4.

29. Weigelt B, Eberle C, Cowell CF, Ng CK, Reis-Filho JS. Metaplastic breast carcinoma: More than a special type. Nat Rev Cancer 2014;14:147-8. 